\title{
Composite Surface for Blocking Bacterial Adsorption on Protein Biochips
}

\author{
Tom T. Huang ${ }^{1,7}$ Jennifer Sturgis ${ }^{2}$ Rafael Gomez, ${ }^{3}$ Tao Geng, ${ }^{4}$ \\ Rashid Bashir, ${ }^{3,5}$ Arun K. Bhunia, ${ }^{4}$ J. Paul Robinson, ${ }^{2,5}$ Michael R. Ladisch ${ }^{5-7}$ \\ ${ }^{1}$ School of Chemical Engineering, \\ ${ }^{2}$ Department of Basic Medical Sciences, \\ ${ }^{3}$ School of Electrical and Computer Engineering, \\ ${ }^{4}$ Molecular Food Microbiology Laboratory, Department of Food Science, \\ ${ }^{5}$ Department of Biomedical Engineering, \\ ${ }^{6}$ Department of Agricultural and Biological Engineering, and \\ 7 Laboratory of Renewable Resources Engineering, Purdue University, West \\ Lafayette, Indiana 47907; telephone: 765-494-7022; fax: 765-494-7023; \\ e-mail: ladisch@ecn.purdue.edu
}

Received 26 April 2002; accepted 22 July 2002

DOI: 10.1002/bit.10507

\begin{abstract}
The design and fabrication of protein biochips requires characterization of blocking agents that minimize nonspecific binding of proteins or organisms. Nonspecific adsorption of Escherichia coli, Listeria innocua, and Listeria monocytogenes is prevented by bovine serum albumin (BSA) or biotinylated BSA adsorbed on $\mathrm{SiO}_{2}$ surfaces of a biochip that had been modified with a $\mathrm{C}_{18}$ coating. Biotinylated BSA forms a protein-based surface that in turn binds streptavidin. Because streptavidin has multiple binding sites for biotin, it in turn anchors other biotinylated proteins, including antibodies. Hence, biotinylated BSA simultaneously serves as a blocking agent and a foundation for binding an interfacing protein, avidin or streptavidin, which in turns anchors biotinylated antibody. In our case, the antibody is C11E9, an IgG-type antibody that binds Listeria spp. Nonspecific adsorption of another bacterium, Escherichia coli, is also minimized due to the blocking action of the BSA. The blocking characteristics of $\mathrm{BSA}$ adsorbed on $\mathrm{C}_{18^{-}}$ derivatized $\mathrm{SiO}_{2}$ surfaces for construction of a protein biochip for electronic detection of pathogenic organisms is investigated. (C) 2003 Wiley Periodicals, Inc. Biotechnol Bioeng 81: 618-624, 2003.
\end{abstract}

Keywords: biochips; protein adsorption; bovine serum albumin (BSA); biotinylated BSA; blocking agent; nonspecific adsorption

\section{INTRODUCTION}

Proteins and antibodies immobilized on microfabricated surfaces of computer chips, with channels through which microliter quantities of fluid are conveyed, can be called microfluidic protein biochips. These devices contain wells with electrodes that can detect living organisms by measurement of impedance. The impedance spectroscopy is an

Correspondence to: M. Ladisch

Contract grant sponsor: Agriculture Research Service of the USDA

Contract grant number: 1935-42000-035 accepted method of the Association of Official Analytical Chemists (AOAC) for detecting bacteria in clinical, food, and industrial samples (Gibson et al., 1992; Ivenitski et al., 1999). Placement of a biospecific receptor (protein) on the chip surface enables preferential capture of a target species (Bashir et al., 2001; Gomez et al., 2001). Listeria monocytogenes, a gram-positive, rod-shaped, food-borne pathogen, is the target addressed in the present study. This bacterium causes serious food poisoning (Farber and Peterkin, 1991) and has been the subject of studies for its detection (Bhunia et al., 2001). In principle, other targets can be captured and detected, by placing the appropriate bioreceptor on the chip, and by minimizing nonspecific adsorption.

A necessary characteristic of a protein biochip is that adsorption of microorganisms, other than the target organism, be blocked. Because many detection techniques, such as impedance spectroscopy, detect only the presence of organisms, and are not capable of distinguishing between species, capture of a target organism will be obscured if other (nontarget) organisms are retained on surfaces to which the bioreceptor is attached. The oxide surfaces of the chip will adsorb a wide range of bacterial species, and hence the surfaces must be modified to avoid this. Bovine serum albumin (BSA) is often used in traditional immunoassays to block uncoated surface sites and to reduce nonspecific adsorptions (Peterfi and Kocsis, 2000). BSA adsorbed on the material surface has been shown to inhibit bacterial adhesion to polymer (Paulsson et al., 1993; Pringle and Fletcher, 1986), ceramic (Gibbons and Etherden, 1983), and metal (An et al., 1995, 1996) surfaces. The degree of inhibitory effects depends on the type of the bacteria and the quality of the surfaces. This investigation examines the use of BSA or biotinylated BSA as the blocking agent placed on a surface consisting of a closely packed, chemically robust, alkylsiloxane $\left(\mathrm{C}_{18}\right)$ monolayer, while using biotinylated BSA as a 
support for anchoring bioreceptors through streptavidin and biotin interactions. A sandwich-type layering effect is shown in Figure 1.

\section{MATERIALS AND METHODS}

Attachment of proteins on the silica $\left(\mathrm{SiO}_{2}\right)$ surface of chips was carried out as described by Mooney et al. (1996). They demonstrated the functionality of biotinylated goat antibodies using fluorescently labeled mouse immunoglobulin $\mathrm{G}$ (IgG) as reporter molecules. The $\mathrm{SiO}_{2}$ surfaces were first derivatized with octadecyltrichlorosilane (ODTS) to form a $\mathrm{C}_{18}$ surface. Biotinylated $\mathrm{BSA}$ was adsorbed onto a $\mathrm{C}_{18}$ modified hydrophobic silica surface. After washing, the streptavidin was adsorbed onto the biotinylated BSA. The role of streptavidin was to capture biotinylated monoclonal antibody, enabling it to contact and capture Listeria monocytogenes cells. Although there are many covalent attachment schemes for biotin or streptavidin, this work addresses a sandwich scheme for the $\mathrm{C}_{18}$-modified surface and presents the results based on validating methods, including fluorescence microscopy and surface plasmon resonance. Conditions that result in nonspecific binding and blocking of nonspecific binding were then determined.

\section{Proteins, Buffer, Bacteria, and Antibody}

Fluorescein isothiocyanate (FITC) labeled BSA was used to test protein adsorption on a $\mathrm{C}_{18}$-modified silica surface. FITC labeled and unlabeled BSA were purchased from Sigma-Aldrich (Cat. \#A-9771, Lot \#89H7613 and Cat. \#A0281, Lot \#100K7415, respectively). Biotinylated bovine serum albumin (BSA) with $8 \mathrm{~mol}$ of biotin attached to each mole of BSA (Cat. \#29130, Lot \#CC48629) and FITC labeled and unlabeled streptavidin and FITC labeled biotin (Cat. \#22030, Lot \#AK42310; Cat. \#21224, Lot \#BH44559; and Cat. \#21122, Lot \#CD48452, respectively) were all purchased from Pierce (Rockford, IL). Phosphate-buffered saline (PBS) buffer ( $\mathrm{pH}$ 7.2) was from a reagent package purchased from Sigma-Aldrich (Cat \#1000-3). Sorensens's phosphate buffer ( $\mathrm{pH} 4.9$ ) was made by adding $0.6 \mathrm{~mL}$ of $0.0837 M$ dibasic sodium phosphate to $96.4 \mathrm{~mL}$ of $0.0667 M$ monobasic potassium phosphate.

The bacterial cultures of Escherichia coli ATCC51379,

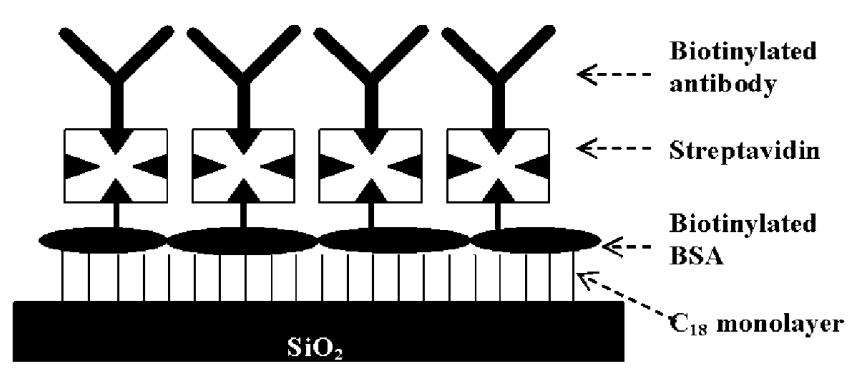

Figure 1. Illustration of protein and antibody attachment on a $\mathrm{SiO}_{2}$ surface modified with $\mathrm{C}_{18}$ end groups (drawing is not to scale).
Listeria monocytogenes V7, and Listeria innocua NCTC11288 were used in this study. L. innocua is a nonpathogenic species, which is otherwise similar to pathogenic L. monocytogenes.

Monoclonal antibody (MAb) C11E9 belongs to the IgG2b subclass. It is produced from mice and binds to the surface proteins of L. monocytogenes and L. innocua in immunoassays (Bhunia et al., 1991; Bhunia, 1997). Purification was performed by protein $\mathrm{G}$ immunoaffinity chromatography using the Acta Prime Liquid Chromatography System (Pharmacia Corp., Peapack, NJ). MAb C11E9 was conjugated with biotin to form biotinylated antibody. The procedure for antibody biotinylation followed the instructions from the manufacturer (Pierce), as modified by Hnatowich et al. (1987). The final antibody/protein concentration was found to be $1.2 \mathrm{mg} / \mathrm{mL}$, by measuring its absorbance at $280 \mathrm{~nm}$. The biotinylated antibody was diluted with PBS buffer ( $\mathrm{pH} \mathrm{7.2)} \mathrm{containing} 1 \mathrm{mg} / \mathrm{mL}$ of BSA and the final antibody concentration was calculated to be $50 \mu \mathrm{g} / \mathrm{mL}$. FITC labeled goat anti-mouse IgG from Sigma-Aldrich (Cat. \#F5262, Lot \#050K4888) was used to probe the nonspecific binding characteristics of the biotinylated BSAcoated surface and streptavidin.

\section{Culture and Labeling of Listeria and E. coli Microbial Cells}

E. coli, L. monocytogenes, and L. innocua, were grown in brain-heart infusion broth (Becton Dickinson, Cockeysville, MD) at $37^{\circ} \mathrm{C}$ for 16 to $18 \mathrm{~h}$. E. coli and Listeria cell concentrations were determined to be approximately $5 \times 10^{9}$ $\mathrm{CFU} / \mathrm{mL}$ and $5 \times 10^{8} \mathrm{CFU} / \mathrm{mL}$, respectively, using serial dilution of samples, with $100 \mu \mathrm{L}$ of each dilution plated out. Cells harvested at this stage have similar properties, particularly at the cell surface, which are responsible for ligand and receptor interactions.

The cells were labeled with FITC fluorescent dye from Sigma-Aldrich (Cat. \#F-4274, Lot \#70K2617). It was dissolved in $0.1 \mathrm{M}$ carbonate bicarbonate buffer at a concentration of $2 \mathrm{mg} / \mathrm{mL}$. After filter sterilization using a 0.45$\mu \mathrm{m}$ size filter (Gelman Sciences, Inc., Ann Arbor, MI), 1 $\mathrm{mL}$ of FITC solution was combined with centrifuged cells (from $10^{8}$ to $10^{9}$ cell $/ \mathrm{mL}$ ) in a $1.5-\mathrm{mL}$ Eppendorf tube and incubated at $37^{\circ} \mathrm{C}$ for $30 \mathrm{~min}$. After incubation, the cells were centrifuged again and then washed three times with 1 $\mathrm{mL}$ PBS buffer to remove unbound FITC molecules.

\section{Microchip Preparation}

A 3-in. wafer patterned with silicon dioxide and platinum was microfabricated as described by Bashir et al. (2001). Plasma-enhanced chemical vapor deposition (PECVD) using silane $\left(\mathrm{SiH}_{4}\right)$ and nitrous oxide $\left(\mathrm{N}_{2} \mathrm{O}\right)$ sources deposited a hydrogen-rich silicon oxide layer on top of the oxidized wafer. The wafer was immersed in acetone for $15 \mathrm{~min}$ to remove photoresist remaining from the fabrication process, and then rinsed three times in methanol to remove acetone 
and three times in deionized water to remove methanol. The wafer was then diced into individual chips with dimensions of 0.15 in. $\times 0.15$ in. using a dicing saw (Model 602, Tempress). A Branson Series 3000 oxygen plasma barrel etcher removed carbon contamination from the chips' surface and resulted in a hydrophilic silica surface with a contact angle for deionized water of between $2^{\circ}$ and $5^{\circ}$. The contact angle measurements were made using a Ramé--Hart contact angle goniometer (Model \#100-00).

$\mathrm{C}_{18}$ alkyl end groups were placed on the hydrophilic chips after the cleaned chips were placed in deionized water overnight to fully hydrate the surface. A hydrated silica surface is needed because it hydrolyzes the ODTS and forms a more stable and homogeneous film than obtained with a nonhydrated surface (Flinn et al., 1994; Hair and Tripp, 1995; Le Grange and Markham, 1993). Nonetheless, before silanizing the surface with ODTS, the hydrated surface was blown dry with nitrogen to remove the mobile water that would otherwise react with the ODTS and cause it to polymerize rather than react with the surface. The freshly prepared chips were then transferred into a Pyrex Petri dish in a $0.5 \%$ (v/v) solution of ODTS (Cat. \#SIO66440.0, Gelest) in anhydrous toluene (Cat. \#24,4511, Lot JO03646EO, Sigma-Aldrich). This was done in a nitrogen-purged glove bag to minimize exposure of ODTS solution to atmospheric water vapor, which reacts with ODTS to form an undesirable organo-silicon polymer. Chips were immersed in the solution for $16 \mathrm{~h}$ and then washed three times with toluene to remove residual ODTS. The chips were then blown dry with nitrogen and baked in an oven at $120^{\circ} \mathrm{C}$ for $30 \mathrm{~min}$ to complete formation of an $\mathrm{Si}-\mathrm{O}$ bond. ODTS-silanized chips were placed in a Petri dish covered with aluminum foil and stored in a nitrogenpurged box until these were used. Contact angle measurements made on the ODTS-silanized surface using deionized water gave a contact angle of between $105^{\circ}$ and $110^{\circ}$.

\section{Fluorescence Microscopy}

\section{Proteins, Antibody, and Bacteria Adsorption Protocols}

Adsorption protocols involved incubation of labeled or unlabeled protein, antibody, or bacterial cells with the chips at room temperature in a 48-well polystyrene plate purchased from Falcon (Cat. \#353078). The chips were rinsed three times in buffer for $5 \mathrm{~min}$ each to wash off unbound protein or bacterial cells from the previous step.

Biotinylated BSA and FITC labeled and unlabeled BSA were diluted to a concentration of $2 \mathrm{mg} / \mathrm{mL}$ using PBS buffer ( $\mathrm{pH}$ 7.2). FITC labeled streptavidin, FITC unlabeled streptavidin, and FITC labeled biotin were diluted to a concentration of $1 \mathrm{mg} / \mathrm{mL}$ using PBS buffer. For studies of BSA adsorption at a different pH (4.9), Sorensen's phosphate buffer with $\mathrm{pH} 4.9$ was used. FITC labeled goat antimouse antibody (IgG) at $5 \mathrm{mg} / \mathrm{mL}$ was diluted to $1: 100$ using PBS buffer. FITC labeled bacterial cells were diluted tenfold with PBS buffer to approximately $10^{7}$ to $10^{8}$ cell/ $\mathrm{mL}$ before the incubation.

Each microchip was immersed in $150 \mu \mathrm{L}$ of respective wash buffer in a $1400 \mu \mathrm{L}$ well of 48 -well plate. To initiate incubation, $50 \mu \mathrm{L}$ of respective protein, antibody, or bacterial cells was added in the well and incubated at room temperature using on a rotary shaker at $120 \mathrm{rpm}$. The incubation time for BSA or biotinylated BSA was 30 min, streptavidin $15 \mathrm{~min}$, biotin $15 \mathrm{~min}$, biotinylated antibody $1 \mathrm{~h}$, goat anti-mouse IgG $30 \mathrm{~min}$, BSA $1 \mathrm{~h}$, and bacterial cells 2 h. According to the literature (Mooney et al., 1996), these contact times should give close-to-saturation amounts of adsorption or binding at the indicated experimental conditions. This was later confirmed by surface plasmon resonance in our lab.

Washing steps were done by placing the chips into different wells after incubation. For protein and antibody adsorption, chips were washed three times after each treatment with PBS buffer. To determine whether desorption occurs with change of $\mathrm{pH}$, chips were incubated using a protein solution diluted with Sorensen's buffer ( $\mathrm{pH} 4.9)$ and washed with PBS buffer ( $\mathrm{pH}$ 7.2) thereafter. For the studies of bacterial adsorption, however, chips were washed twice, after each treatment with $0.05 \%$ Tween 20 in PBS, and then washed once in PBS to remove the Tween 20. Tween 20 (polyoxyethylene sorbitan monolaureate) is a nonionic surfactant that effectively suppresses aggregation between antibodies, antigens, and other molecules. In each washing step, the microchip was in contact with the solution for 5 min, while the 48-well plate was agitated on the rotary shaker at $120 \mathrm{rpm}$. The amount of washing solution used for each microchip was $300 \mu \mathrm{L}$ for every washing step.

\section{Fluorescence Image Analysis}

After washing, the microchips were placed into chambers made from a durable silicone gasket. The silicone gasket was patterned with squares and then pressed against a microscope slide to form an imaging chamber. To keep the proteins and cells from drying, a few drops of PBS buffer were placed onto the microchip surface. A coverslip was used to seal the imaging chambers before the fluorescence images were collected.

The fluorescence images were observed in a Nikon Labophot fluorescence microscope with a FITC filter and an Optronics 470T CCD camera, and acquired with METAMoRPH software (Universal Imaging Corp., Downingtown, PA). The fluorescence label (FITC) has an emission peak between 515 and $525 \mathrm{~nm}$, which was the region collected. The fluorescence signal was quantified using Adobe PHOTOSHOP v5.5 (Adobe Systems, Inc., San Jose, CA). The Adobe software also outputs statistical information regarding the fluorescence intensity of an image based on a dimensional area of $100 \times 100$ pixels, with each pixel representing a dimension of $4.35 \mu \mathrm{m}$ on the actual microchip. The intensity and statistics enabled comparison of the de- 
gree of adsorption on the various surfaces within each particular experiment. A comparison was also made with intensity from images of untreated surfaces. The intensity of the emission should be directly proportional to the amount of adsorbed protein on the surface. Since the signals collected are 8 bit, intensity calculations were made excluding fully saturated signals at channel 225 . Intensity results were compared to the results obtained for the BSA absorption onto a hydrophilic surface at $\mathrm{pH}$ 4.9. For each experiment, fluorescence results from three different microchips were combined to calculate an average emission, and a standard deviation for the measurement.

To interpret fluorescence results involving the adsorption of $E$. coli or Listeria cells, the number of E. coli or Listeria cells, adsorbed or bound, was obtained by visually counting the number of labeled cells after chips were washed three times with the buffer. A $100 \times 100$ pixel area on the picture was used for counting the number of cells. Any cells inside this area were counted. To be consistent with the computation, only the areas with the highest cell counts were used. The final number was an average from three chips on which cells from a single $100 \times 100$ pixel area on each chip were counted.

\section{Surface Plasmon Resonance Measurements Using Cuvettes}

Surface plasmon resonance (SPR) measurements were performed on an IAsys Plus Dual-Well Optical Biosensor (Thermo BioAnalysis Corp., Cambridge, UK). The IAsys system consists of a cuvette (pre-derivatized with aminosilane, carboxylate, biotin, or hydrophobic groups), a resonant mirror to detect the binding or dissociation, and a computer for data acquisition. A cuvette with a hydrophobic surface and another cuvette with biotin surface were used in this work. Reagents can be injected into the cuvette for the binding events to take place. The resonance mirror produces a signal related to the change in the refractive index and this allows the computer to interpret the signal and plot out the results. The change in the refractive index serves as an indicator corresponding to the amount of protein immobilized onto the sensor surface. According to the calibration data provided by IAsys, the sensitivity of the hydrophobic cuvette and biotin cuvette were both 600 arc seconds per nanogram per square millimeter of protein bound.

The hydrophobic IAsys cuvette was first washed three times with $60 \mu \mathrm{L}$ of PBS buffer ( $\mathrm{pH}$ 7.2) and then 5 min of baseline data were obtained. The stirrer rate of the cuvette was set to be $85 \%$ while the temperature was maintained at $22^{\circ} \mathrm{C}$. A volume of $40 \mu \mathrm{L}$ of biotinylated BSA at $2 \mathrm{mg} / \mathrm{mL}$ was then pipetted into the cuvette with $60 \mu \mathrm{L}$ of PBS buffer already added. The biotinylated BSA was then left in cuvette for $30 \mathrm{~min}$. The cuvette was then washed with $60 \mu \mathrm{L}$ of PBS buffer. Next, $20 \mu \mathrm{L}$ of $1 \mathrm{mg} / \mathrm{mL}$ streptavidin was added. PBS buffer was again used to remove excess strep- tavidin. Finally, the cuvette was injected with $20 \mu \mathrm{L}$ of $50-\mu \mathrm{g} / \mathrm{mL}$ biotinylated antibody (C11E9).

The extent of adsorption of biotinylated BSA on the hydrophobic cuvette surface depends on the hydrophobicity of the surface and on the concentration of surfactant, such as Tween 20, in the buffer. Zhang and Ferrari (1997) found that $0.05 \%$ Tween 20 can induce a $90 \%$ reduction in albumin adsorption on hydrophobic methylated surfaces. Consequently, no surfactant was used in these runs.

A purchased cuvette that had been covalently derivatized with biotin was washed three times with $60 \mu \mathrm{L}$ of PBS buffer ( $\mathrm{pH}$ 7.2) to obtain instrument baseline. Then, $20 \mu \mathrm{L}$ of streptavidin at $1 \mathrm{mg} / \mathrm{mL}$ was added into the cuvette in addition to the $60 \mu \mathrm{L}$ of PBS buffer already added. Next, the cuvette was washed three times with PBS buffer to remove excess unbound streptavidin. Finally, the cuvette was injected with $20 \mu \mathrm{L}$ of $50-\mu \mathrm{g} / \mathrm{mL}$ biotinylated antibody (C11E9).

\section{RESULTS AND DISCUSSION}

FITC labeled BSA in contact with cleaned, hydrophilic chips gave minimal adsorption at $\mathrm{pH}$ 7.2. The measured fluorescence was only slightly higher than that of a blank chip wetted with buffer, whereas chips with the hydrophobic $\mathrm{C}_{18}$ surface gave significant adsorption of BSA protein (compare Fig. 2a and b). At $\mathrm{pH} \mathrm{4.9,} \mathrm{the} \mathrm{chips} \mathrm{with} \mathrm{the}$ hydrophilic surface (Fig. 2d) adsorbed a significant amount of BSA, although it was easily removed by simply washing the chip with pH 7.2 buffer (compare bars in Fig. 2d and e). Significant adsorption occurs on hydrophilic surfaces at close to the isoelectric point of BSA (pI 4.8), but not at $\mathrm{pH}$ $7.2(\mathrm{pH}$ at which BSA is negatively charged and is less likely to adsorb on the negatively charged $\mathrm{SiO}_{2}$ surface).

Streptavidin adsorbed onto a hydrophobic chip coated with biotinylated BSA (Fig. 3b). Labeled biotin also adsorbed onto a chip coated with streptavidin at $\mathrm{pH} 7.2$ (bar in Fig. 3c). The results show that the streptavidin/biotin pairs bound at the surface of the chip. The lower extent of binding

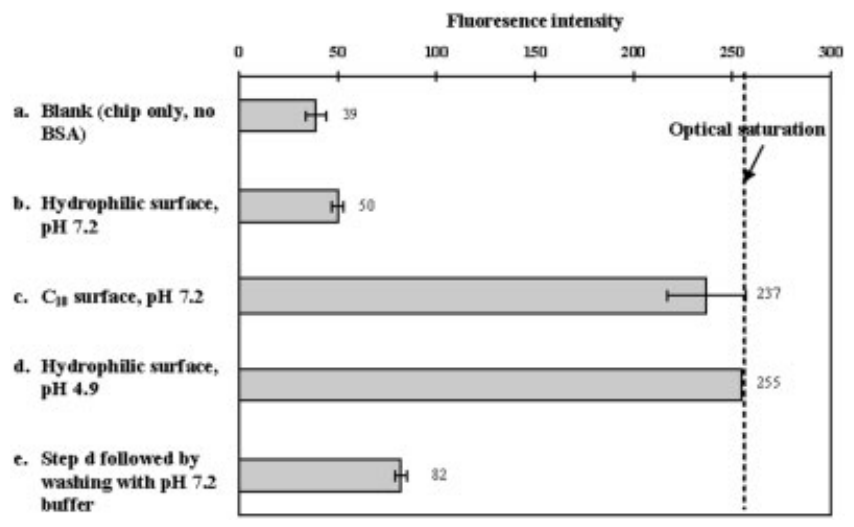

Figure 2. Fluorescence intensity comparisons for BSA adsorption to chips with hydrophilic or $\mathrm{C}_{18}$ surfaces at various experimental conditions. 


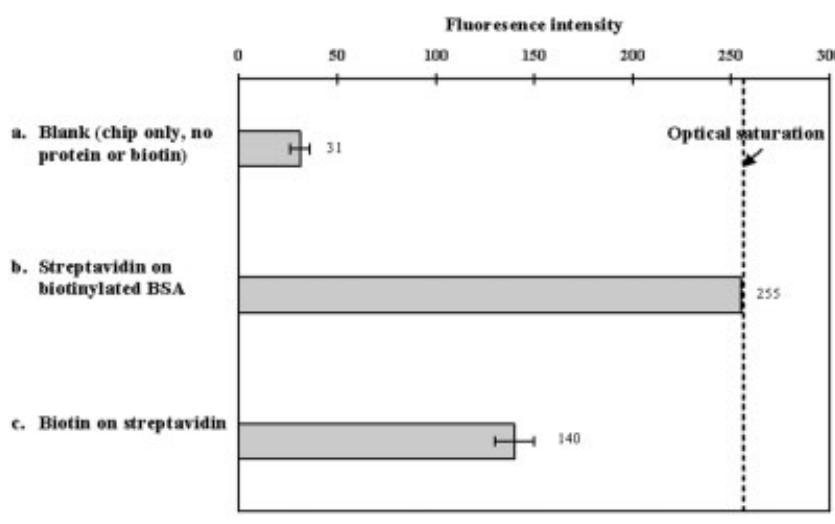

Figure 3. Fluorescence intensity comparisons for streptavidin and biotin binding to chips with $\mathrm{C}_{18}$ surfaces carried out at $\mathrm{pH} 7.2$, and incubation for 15 min.

of the biotin likely reflects steric factors wherein the biotin (MW $244 \mathrm{Da}$ ) was not as accessible to the binding pocket on the streptavidin (streptavidin MW 60,000 Da), which has four possible binding sites, of which at least one, and up to three sites would be readily accessible to the labeled biotin molecules.

Goat anti-mouse $\operatorname{IgG}$ adsorption at $\mathrm{pH} 7.2$ was minimal for hydrophobic surfaces coated with biotinylated BSA or streptavidin (compare Fig. 4a, b, and c). IgG adsorbed strongly on the $\mathrm{C}_{18}$-derivatized surface (bar in Fig. 4d). Hydrophobic regions of the $\mathrm{IgG}$ binding with hydrophobic regions on the chip may have accounted for this effect.

Fluorescence images for bacterial adsorption are given in Figure $5 \mathrm{a}-\mathrm{d}$, which shows that BSA blocks or minimizes the binding of E. coli and L. innocua cells. In contrast, E. coli and $L$. innocua strongly adsorbed on the $\mathrm{C}_{18}$ hydrophobic surface. The tabulated results for bacterial adsorption on various surfaces are listed in Table I. Biotinylated BSA was seen to block or minimize binding of bacterial cells as effectively as BSA. E. coli, L. innocua, and L. monocytogenes exhibited extensive binding to streptavidin at $\mathrm{pH}$ 7.2. A

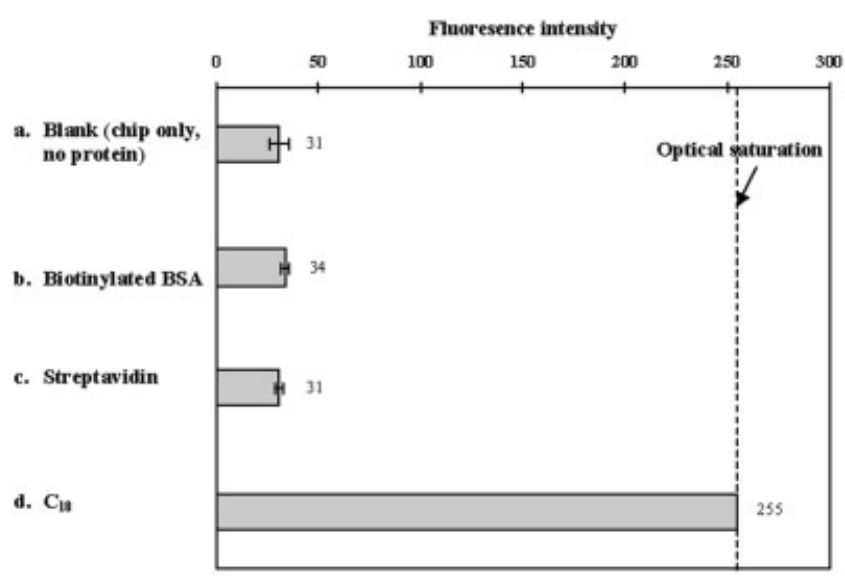

Figure 4. Fluorescence intensity comparisons for nonspecific binding of goat $\mathrm{IgG}$ antibody to chips with $\mathrm{C}_{18}$ surfaces carried out at $\mathrm{pH}$ 7.2, and incubation for $30 \mathrm{~min}$.
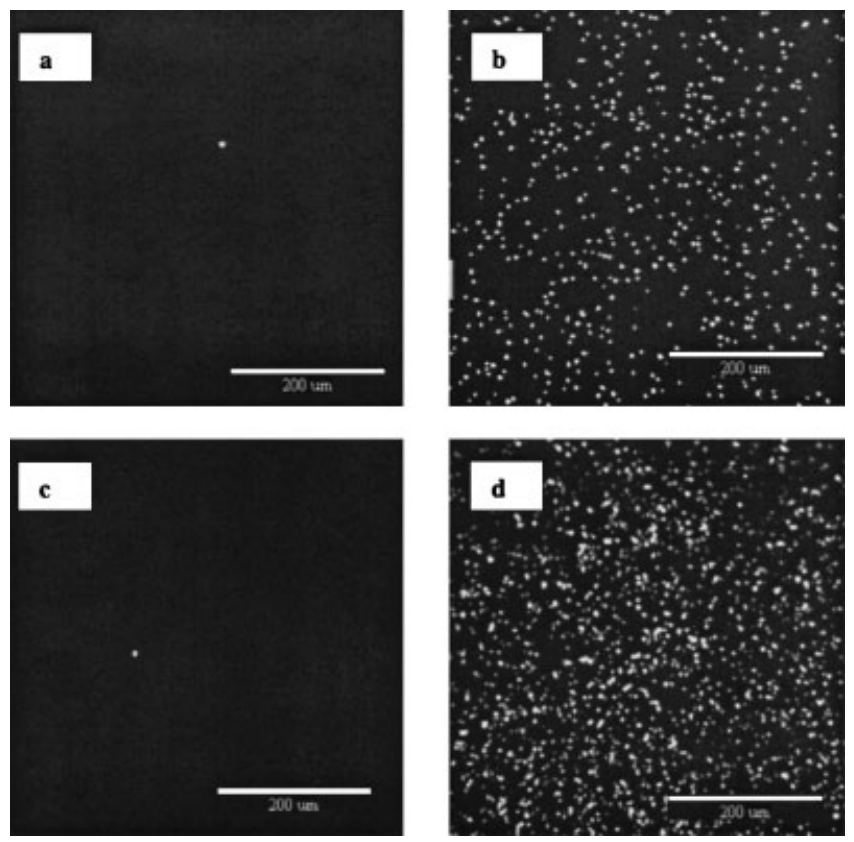

Figure 5. Fluorescence images of bacterial adsorption: E. coli adsorption to a BSA-coated surface (a) and a $\mathrm{C}_{18}$ surface (b). Listeria innocua adsorption to a BSA-coated surface (c) and a $\mathrm{C}_{18}$ surface (d) (scale bar 200 $\mu \mathrm{m})$.

possible explanation for this is that streptavidin contains a tripeptide sequence, Arg-Tyr-Asp (RYD), that mimics the Arg-Gly-Asp (RGD) binding sequence of fibronectin, a component of the extracellular matrix that promotes cellular adhesion (Alon et al., 1993). When the streptavidin is treated with BSA, the binding of the Listeria monocytogenes is reduced over twofold further, confirming the blocking action of BSA. For specific binding between antibody and L. monocytogenes, the biotinylated antibody (C11E9) was placed on the streptavidin. This resulted a higher capture of $L$. monocytogenes at around 60 cells than for streptavidin alone.

Plasmon resonance measurements (Wilson, 2002) further showed how strong and rapid adsorption of streptavidin (1 $\mathrm{mg} / \mathrm{mL}$ from a volume of $20 \mu \mathrm{L}$ liquid) occurs onto a cuvette surface preimmobilized with biotinylated BSA. Using this technique, the amount of streptavidin immobilized onto the hydrophobic cuvette surface was estimated to be $2 \mathrm{ng} /$ $\mathrm{mm}^{2}$. This is equivalent to the amount of streptavidin immobilized onto an IAsys biotin cuvette surface with covalently attached biotin, having approximately the same sur-

Table I. Number of bacterial cells adsorbed on various surfaces in a 435 $\mu \mathrm{m} \times 435 \mu \mathrm{m}\left(189,225 \mu \mathrm{m}^{2}\right)$ area.

\begin{tabular}{lccc}
\hline \multicolumn{1}{c}{ Protein-coated surface } & E. coli & $\begin{array}{c}\text { Listeria } \\
\text { innocua }\end{array}$ & $\begin{array}{c}\text { Listeria } \\
\text { monocytogenes }\end{array}$ \\
\hline Biotinylated BSA & 1 & 2 & 2 \\
Streptavidin & 25 & 30 & 45 \\
Streptavidin blocked by BSA & 9 & 15 & 20 \\
\hline
\end{tabular}




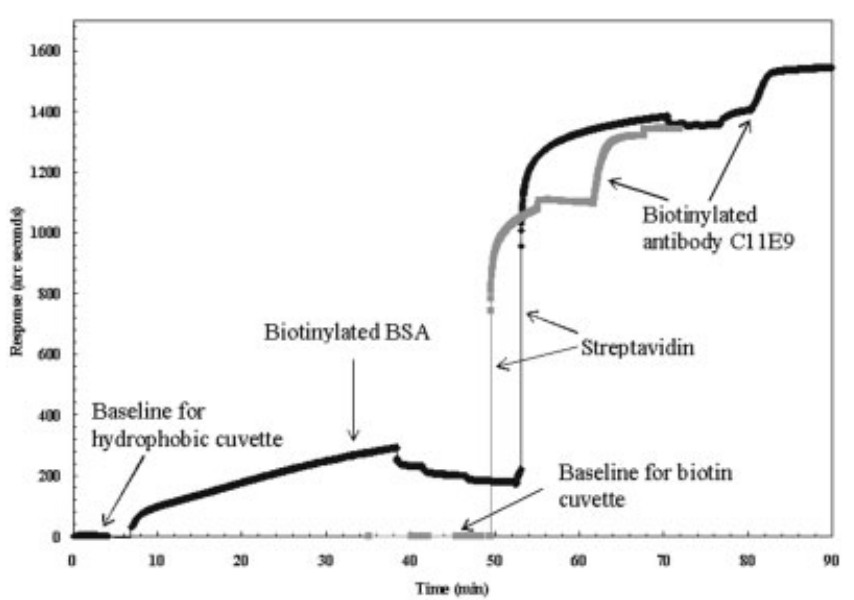

Figure 6. Surface plasmon resonance results of streptavidin/biotin interaction at pH 7.2 using the IAsys cuvette with a hydrophobic surface and a covalently derivatized biotin surface.

face area (Fig. 6). Capture of the biotinylated antibody (C11E9) by streptavidin was also observed. Results from surface plasmon resonance (SPR) confirm that a surface coated with biotinylated BSA can effectively anchor the biotinylated antibody due to the affinity between streptavidin and biotin. The SPR results also show that protein (streptavidin) adsorption was fast for a clean surface (response occurs in $<2 \mathrm{~min}$ ), whereas binding of the antibody onto protein was much slower (requiring approximately 15 to $20 \mathrm{~min}$ ). The curved part of the response curve reflects the adsorption characteristic of the protein at local equilibrium (Ladisch, 2001).

\section{CONCLUSIONS}

The principles of adsorption needed to fabricate practical protein biochips were examined in this work. Reproducible methods for direct adsorption of protein on the chips suggest an attachment scheme of physical adsorption of a layer of biotinylated BSA onto a $\mathrm{C}_{18}$-modified hydrophobic surface. The biotinylated microchip surface promotes rapid and efficient capture of a monolayer of streptavidin. The unoccupied biotin-binding sites on streptavidin are then used to capture a biotinylated monoclonal antibody (C11E9) that is specific for capturing of the food-borne pathogen, Listeria monocytogenes. Using a surface plasmon resonance apparatus and an already-provided hydrophobic surface, the feasibility of this attachment scheme was validated, and contact times of 15 to $30 \mathrm{~min}$ for protein adsorption during preparation of the chip can be suggested. To characterize the actual protein, antibody, and adsorption of bacterial cells to the microchips, fluorescently labeled proteins, antibody, and bacterial cells were used, and fluorescence images were obtained using a fluorescence microscope.

Biotinylated BSA adsorbs strongly onto the $\mathrm{C}_{18}$-modified silica surface at $\mathrm{pH} 7.2$ through hydrophobic interactions.
Its activity is maintained, as indicated by the strong adsorption of streptavidin. Subsequent capture of fluorescently labeled biotin by streptavidin indicated that biotinylated antibody could be attached to the surface with success. Binding studies performed later showed that the biotinylated BSA had low nonspecific binding to the $\operatorname{IgG}$ antibody, $E$. coli, and Listeria cells, whereas streptavidin alone bound both E. coli, L. monocytogenes, and L. innocua. Blocking of the streptavidin with BSA reduced this adsorption. Then, when biotinylated antibody C11E9 was fixed to the surface, specific binding of L. monocytogenes occurred. This work has demonstrated the feasibility and utility of using BSA or biotinylated $\mathrm{BSA}$ on the $\mathrm{C}_{18}$-derivatized $\mathrm{SiO}_{2}$ surface to inhibit nonspecific adsorption of antigens, and has also provided a scaffold or foundation for binding an interfacing protein, avidin or streptavidin, which in turn anchors biotinylated bioreceptors.

The authors thank Saad Asrar, Anjali Gaba, and Dr. Ann Rundell for helpful comments and suggestions during the preparation of this work. We also thank T. Miller, Dr. Jack Denton, D. Lubelski, and B. Crabill of the microelectronic facility at Purdue University, where the chip was prepared, as well as Amanda Lathrop for her help with the SPR and Sang-won Lee for his help with the contact angle measurement.

\section{References}

Alon R, Bayer EA, Wilchek M. 1993. Cell adhesion to streptavidin via RGD-dependent integrins. Eur J Cell Biol 60:1-11.

An YH, Friedman RJ, Draughn RA, Smith EA, Nicholson J, John JF. 1995 Rapid quantification of staphylococci adhered to titanium surface using image analyzed epifluoresence microscopy. J Microbiol Meth 24: 29-40.

An YH, Stuart GW, McDowell SJ, McDaniel SE, Kang Q, Friedman RJ. 1996. Prevention of bacterial adherence to implant surfaces with a cross-linked albumin coating in vitro. J Orthop Res 14:846-849.

Bashir R, Gomez R, Sarikaya A, Ladisch MR, Sturgis J, Robinson JP. 2001. Adsorption of avidin on microfabricated surfaces for protein biochip applications. Biotechnol Bioeng 73:324-328.

Bhunia AK, Ball PH, Fuad AT, Kurz BW, Emerson JW, Johnson MG. 1991. Development and characterization of a monoclonal antibody specific for Listeria monocytogenes and Listeria innocua. Infect Immun 59:3176-3184.

Bhunia AK. 1997. Antibodies to Listeria monocytogenes. Crit Rev Microbiol 23:77-107.

Bhunia AK, Jaradat ZW, Naschansky K, Shroyer M, Morgan M, Gomez R, Bashir R, Ladisch MR. 2001. Impedance spectroscopy and biochip sensor for detection of Listeria monocytogenes. Proc SPIE 4206: 32-39.

Farber JM, Peterkin PI. 1991. Listeria monocytogenes: a food-borne pathogen. Microbiol Rev 55:476-511.

Flinn DH, Guzonas DA, Yoon RH. 1994. Characterization of silica surfaces hydrophobized by octadecyltrichlorosilane. Coll Surf A 87: 163-176.

Gibbons RJ, Etherden I. 1983. Comparative hydrophobicities of oral bacteria and their adherence to salivary pellicles. Infect Immunol 41: 1190-1196.

Gibson DM, Coombs P, Pimbley DW. 1992. Automated conductance method for the detection of Salmonella in foods: collaborative study. J Assoc Off Anal Chem 75:293-297.

Gomez R, Bashir R, Sarikaya A, Ladisch MR, Sturgis J, Robison JP, Geng 
T, Bhunia AK, Apple HL, Wereley ST. 2001. Micro-fluidic biochip for impedance spectroscopy of biological species. Biomed MicroDevices 3:201-209.

Hair ML, Tripp CP. Alkylchlorosilane reaction at the silica surface. 1995. Coll Surf A 105:95-103.

Hnatowich DJ, Virzi F, Ruschowski M. 1987. Investigations of avidin and biotin for imaging applications. J Nucl Med 28:1294-1302.

Ivnitski D, Adel-Hamid I, Atanasov P, Wilkins E. 1999. Review: biosensor for detection of pathogenic bacteria. Biosens Bioelectron 14:599-624.

Ladisch MR. 2001. Bioseparations engineering. New York: John Wiley \& Sons. Le Grange JD, Markham JL. 1993. Effects of surface hydration on the deposition of silane monolayers on silica. Langmuir 9: 1749-1753.

Mooney JF, Hunt AJ, McIntosh JR, Liberko CA, Walba DM, Rogers CT. 1996. Patterning of functional antibodies and other proteins by pho- tolithography of silane monolayer. Proc Natl Acad Sci USA 93: 12287-12291.

Paulsson M, Kober M, Freij-Larsson C, Sollenwerk M, Wesslén B, Ljungh A. 1993. Adhesion of staphylococci to chemically modified and native polymers, and the influence of preadsorbed fibronectin, vitronectin and fibrinogen. Biomaterials 14:845-853.

Peterfi Z, Kocsis B. 2000. Comparison of blocking agents for an ELISA for LPS. J Immunoassay 21:341:354.

Pringle JH, Fletcher M. 1986. Influence of substratum hydration and adsorbed macromolecules on bacterial attachment to surfaces. Appl Environ Microbiol 51:1321-1325.

Wilson WD. 2002. Analyzing biomolecular interactions. Science 295: 2103-2105.

Zhang M, Ferrari M. 1997. Reduction of albumin adsorption onto silicon surfaces by Tween 20. Biotechnol Bioeng 56:618-625. 